\title{
Levonorgestrel intrauterine system in menorrhagia- an effective and acceptable alternative
}

\author{
Barkha A. Bafna*, Amit N. Bafna \\ Department of Obstetrics and Gynecology, Bafna Hospital, Dhule, Maharashtra, India \\ Received: 04 February 2021 \\ Accepted: 06 March 2021 \\ *Correspondence: \\ Dr. Barkha A. Bafna, \\ E-mail: barkhajainbafna@yahoo.com \\ Copyright: (C) the author(s), publisher and licensee Medip Academy. This is an open-access article distributed under \\ the terms of the Creative Commons Attribution Non-Commercial License, which permits unrestricted non-commercial \\ use, distribution, and reproduction in any medium, provided the original work is properly cited.
}

\begin{abstract}
Background: To study the efficacy, performance and acceptability of levonorgestrel intrauterine device (LNG-IUS) in treatment of women with menorrhagia.

Methods: This was a descriptive, prospective and observational study conducted over a period of January 2015 to September 2020. Seventy-five (75) women presented with heavy menstrual bleeding having no contraindication for device underwent LNG-IUS insertion after consent. Menstrual pattern, pictorial blood loss assessment chart score (PBAC), rate of acceptability and satisfaction were recorded at 3 months, 6 months, 1, 2 and 3 years after insertion of LNG-IUS.

Results: The most common bleeding pattern at 3 month post-insertion was inter-menstrual spotting followed by infrequent menses, oligomenorrhea and amenorrhea. LNG-IUS caused $45.19 \%$ reduction in menstrual blood loss (MBL) at 3 months, $81.48 \%$ at 1 year, $91.85 \%$ at 2 years and $97 \%$ at 3 years. Hemoglobin levels improved from mean baseline $8.9 \mathrm{mg} / \mathrm{l}$ to $12.8 \mathrm{mg} / \mathrm{l}$ at 3 years. Majority of women were satisfied with this minimally-invasive treatment with continuation rate of $94.66 \%$. No major side-effects were noted.

Conclusions: LNG-IUS is an excellent minimal invasive, highly effective in controlling blood loss and well-tolerated alternative for women with menorrhagia. Its fertility-sparing property makes it an emerging option for young women.
\end{abstract}

Keywords: Levonorgestrel intrauterine system, Menorrhagia, Pictorial blood loss assessment chart

\section{INTRODUCTION}

Abnormal uterine bleeding is the commonest symptom for which women seek gynecologist's consultation. Menorrhagia is a major cause of discomfort, anxiety, anemia and decreased quality of life of women in their child-bearing age. Menorrhagia is defined as greater than $80 \mathrm{ml}$ blood loss per menstrual cycle. The major causes of menorrhagia are ovulatory disorders, primary endometrial disorders, fibroid, adenomyosis, endometriosis or genital malignancies. ${ }^{1}$ Nearly $30 \%$ of all hysterectomies are performed to alleviate heavy menstrual bleeding (HMB). ${ }^{2}$ Historically, definitive surgical correction has been mainstay of treatment of menorrhagia. But today modern gynecology has trended towards conservative therapy both for controlling treatment costs and the desire of many women to preserve the uterus.

Levonorgestrel releasing intrauterine system (LNG-IUS), a steroid releasing intrauterine system offers a safe, longacting and minimally-invasive alternative to traditional medical and surgical treatments of HMB. It is a T-shaped device that releases levonorgestrel directly into the uterine cavity at an initial rate of $20 \mu \mathrm{g}$ /day up to 5 years. The contraceptive and therapeutic benefits of LNG-IUS stems primarily from its local effects. The major effect on endometrium is that it becomes atrophic and inactive with few glands and scarce mitotic activity. ${ }^{3}$ It also causes local foreign body reaction characterized by an increase 
in inflammatory cells, plasma cells and macrophages. These changes settle down within 3 months of insertion of LNG-IUS. The high contraceptive efficacy is well documented through extensive clinical research. ${ }^{4}$ LNGIUS also confers important non-contraceptive health benefits like the oral contraceptive pills. ${ }^{4}$

This study aimed to evaluate the efficacy of LNG-IUS in treatment of menorrhagia.

\section{METHODS}

Seventy-five (75) women who had menorrhagia were recruited for study from the OPD of Bafna Hospital and Maternity Home, from January 2015 to September 2020. Women were offered the option of LNG-IUS insertion for treatment of HMB after detailed counseling. Informed consent was obtained for each woman prior to procedure. Data was collected prospectively and analyzed.

\section{Inclusion criteria}

All women who diagnosed as abnormal uterine bleeding were explained about the procedure in their language and those who agreed to give consent were included in the study.

\section{Exclusion criteria}

Active genital tract infections. Severe anemia $(\mathrm{Hb} \leq 7 \mathrm{mg} / \mathrm{l})$. Pregnancy. Abnormal cervical cytology. Premalignant and malignant endometrial histology. Previous endometrial resection/ablation. Fibroid $>3$ in number/ $>3 \mathrm{~cm}$ size/ sub mucosal/ distorting the endometrium. Adnexal tumors. Postmenopausal bleeding. Hypersensitivity to levonorgestrel.

A detailed history of demographic profile, obstetric history, previous IUCD use, any medical and surgical illness along with a detailed menstrual history was noted. Subjective assessment of menstrual blood loss was done with pictorial blood loss assessment chart (PBAC) score. The PBAC score is calculated by multiplying the number of pads used with duration of flow with degree of staining 1, 5 and 20 for slight, moderate and heavily soiled pads respectively. PABC score $\geq 100$ was considered as $\mathrm{MBL}>80 \mathrm{ml}$ and as diagnostic of menorrhagia.

Routine investigations included hemogram, sugars, coagulation profile, thyroid function test, gynecological examination. Trans-vaginal sonography was done to evaluate possible cause of menorrhagia like fibroid, adenomyosis, endometrial polyps and endometrial cysts. Cervical cytology and endometrial sampling was done to rule out cervical or endometrial neoplasia. All women had negative pregnancy test prior to insertion of LNGIUS.

LNG-IUS insertion was done post-menstrual within 7 days under i.v. sedation. Patient were observed for any immediate complications and then discharged. After the procedure patient was advised to keep record of the menstrual flow including the number of pads, duration and amount of staining using the PBAC charts. These records were evaluated in subsequent visits along with hemoglobin levels at 3 months, 6 months, 1 year, 2 years and 3 years.

Also, patient satisfaction was recorded on a scale 0-5 with; 0 as 'least satisfied' and 5 as 'most satisfied'. Parameters like general well-being, mental health, effect of menstrual blood loss, adverse effects and overall acceptability were assessed.

The primary outcome included reduction in menstrual blood loss, decrease in dysmenorrhea, incidence of sideeffects and improvement in hemoglobin levels. The secondary outcome was to assess patient satisfaction, acceptability and continuation rate of LNG-IUS for heavy menstrual bleeding.

\section{RESULTS}

In our study, 75 women between 21 to 50 years of age underwent LNG-IUS insertion for menorrhagia and were systematically followed up at regular interval of time. The mean age of participants is 39.53 years. Although majority of women were above 40 years, younger women also showed interest in using this safe, reversible and fertility sparing device (Figure 1).

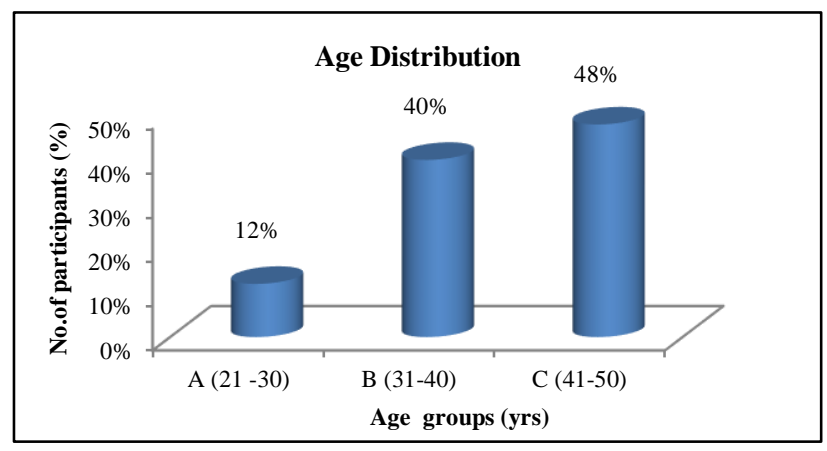

Figure 1: Age distribution.

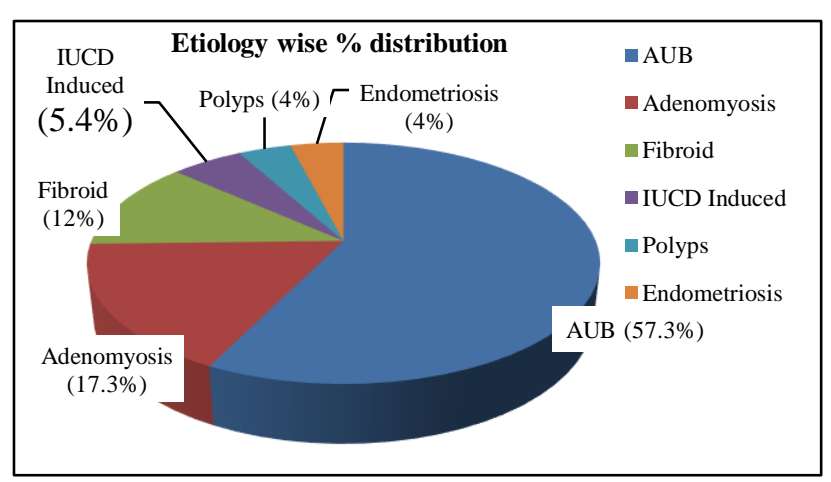

Figure 2: Etiology of menorrhagia. 
Abnormal uterine bleeding (AUB) 57.3\% (43) was found to be the single most common indication of $\mathrm{HMB}$ followed by adenomyosis $17.3 \%$ (13), fibroid $12 \%$ (9), endometriosis $4 \%$ (3) and endometrial polyps $4 \%(n=3)$. Previous copper IUCD-induced menorrhagia 5.3\% (3) was an emerging group who sought for LNG-IUS as an option for their contraceptive needs along with HMB problem due to traditional IUCD use (Figure 2).

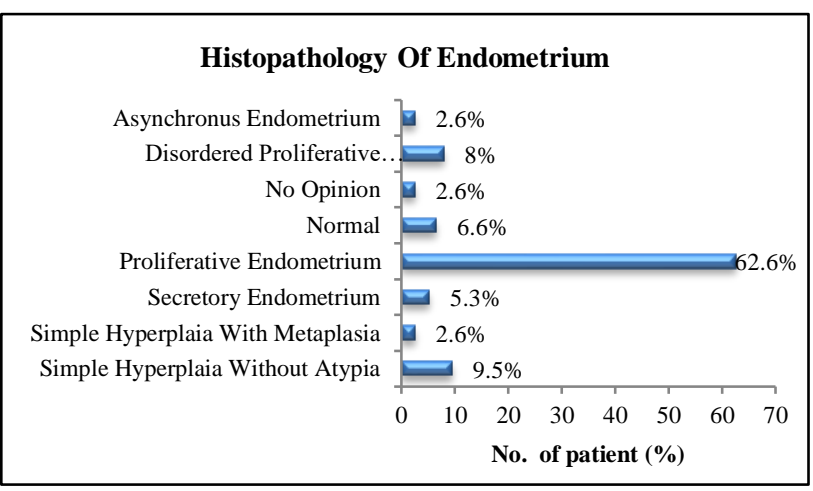

Figure 3: Histopathology of endometrium.

On histopathological examination of endometrial samples $62.6 \%$ (47) patients had proliferative endometrium, 5.3\% (4) with secretary endometrium and 9.3\% (7) with simple hyperplasia without atypia (Figure 3).

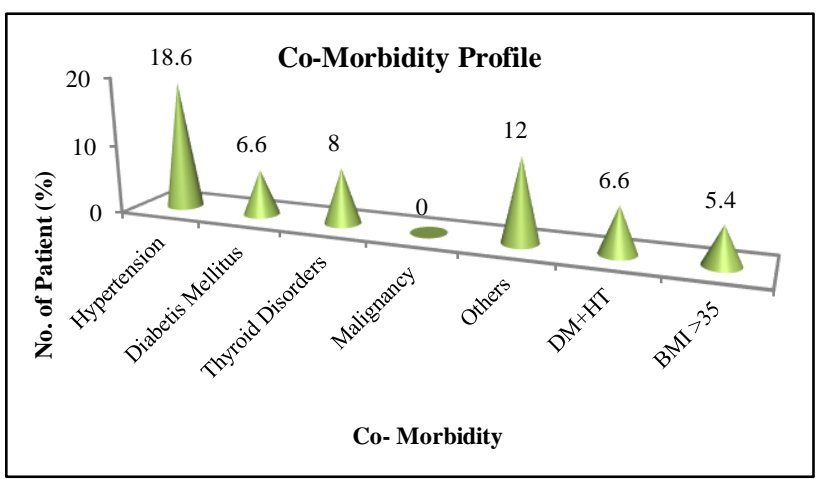

Figure 4: Co-morbidity profile of the participants.

The Co-morbidity profile of the participants is given in Figure 4. Other co-morbidities like Bronchial asthma, Ischemic heart disease, SLE, sarcoidosis, chronic renal disease, chronic liver disease, thalessemia trait were seen in $12 \%$ of participants.

Table 1: Number of patients (n) and duration of follow-up (months/year).

\begin{tabular}{|lll|}
\hline $\begin{array}{l}\text { Follow up } \\
\text { duration }\end{array}$ & Sample size (n) & $\begin{array}{l}\text { Excluded from } \\
\text { F/U }\end{array}$ \\
\hline 3 months & 75 & 3 expulsion \\
\hline 6 months & 72 & 1 removal \\
\hline 1 year & 60 & - \\
\hline 2 years & 43 & - \\
\hline 3/3+ years & 31 & - \\
\hline
\end{tabular}

The number of participants who follow up as an ongoing process is shown in Table 1. Three (4\%) patients had spontaneous expulsion of the device at 3-4 months and one $(1.3 \%)$ patient requested removal at end of 6 months for persistent irregular bleeding. These women later underwent hysterectomy and were excluded from further follow up.

Menstrual blood loss pattern was observed at 3 months, 6 months, 1 year, 2 years and 3 years and found that intermenstrual spotting was most common pattern at 3 months $50.6 \%$ (38) which drastically reduced to as low as $3 \%$ (1) at 3 year use. At end of 3 years follow-up $80.6 \%$ (25) became amenorrhic and $12.9 \%$ (4) had infrequent scanty menses (Figure 5).

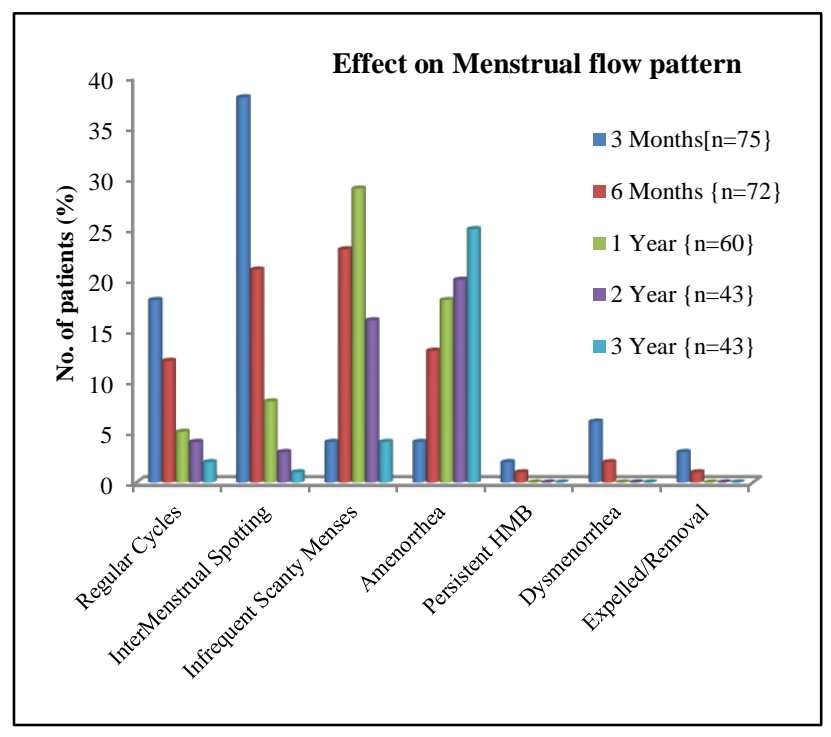

Figure 5: Effect on menstrual flow pattern.

Our study had statistically significant improvement in hemoglobin $(\mathrm{Hb})$ levels. The mean pre-insertion $\mathrm{Hb}$ level was $8.95 \mathrm{mg} / \mathrm{l}$, at 1 year $10.2 \mathrm{mg} / \mathrm{l}$, at 2 year $11.4 \mathrm{mg} / \mathrm{l}$ and at 3 year $12.8 \mathrm{mg} / \mathrm{l}$ (Figure 6).

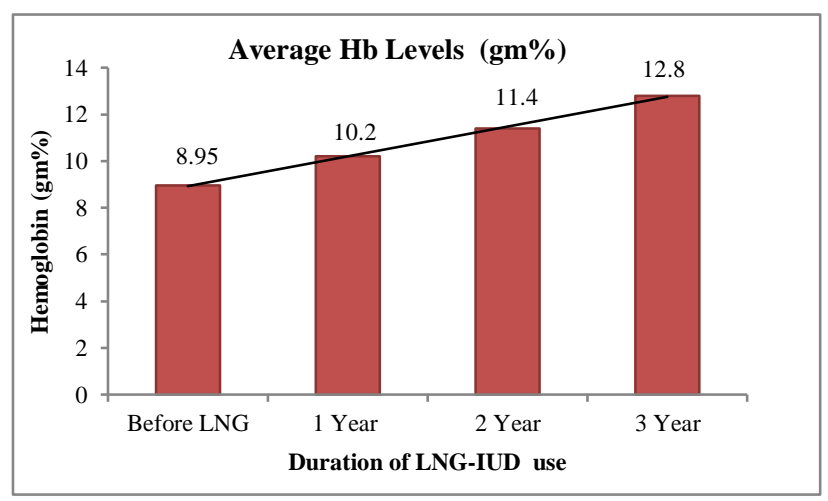

Figure 6: Effect on hemoglobin levels (gm\%).

In our study, no major adverse side-effects were observed (Figure 7). 
Patient education, counselling and re-enforcement at subsequent visits have led to the continuation of use and regular follow up of the patients. Figure 8 shows satisfaction score among the users over the time. At 3 months satisfaction score $>4$ was seen in $64 \%$ which further improved to $93 \%$ after 1year and $96.7 \%$ at 3 years.

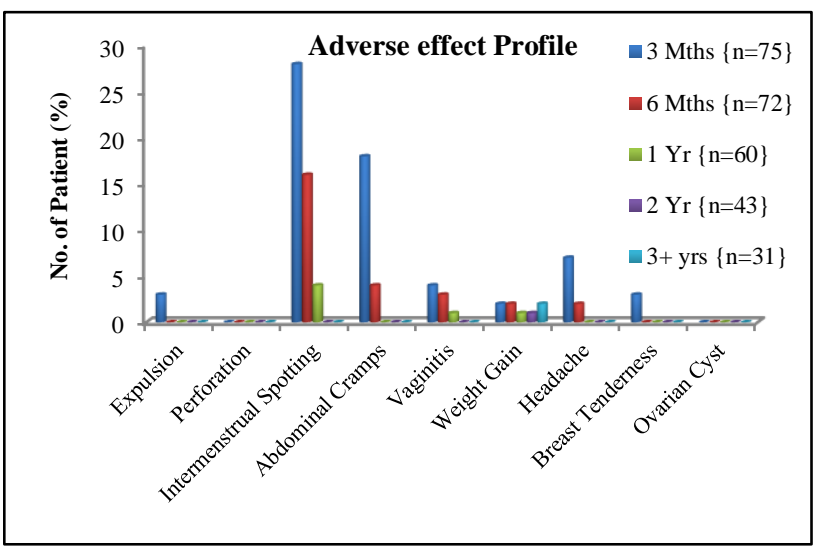

Figure 7: Adverse effect profile.

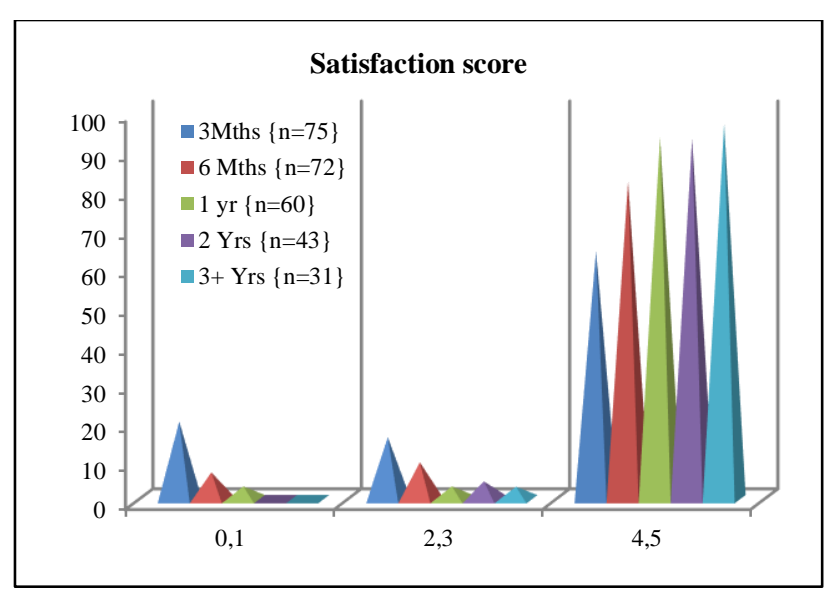

Figure 8: Satisfaction score.

Comparison with various studies available in literature, yielded similar results as ours. Comparison was done in following aspects: 1) Percent (\%) reduction in menstrual blood flow (MBF) (Figure 9). 2) Adverse effect/complication comparison (Table 2). 3) Continuation score and satisfaction score (Table 3).

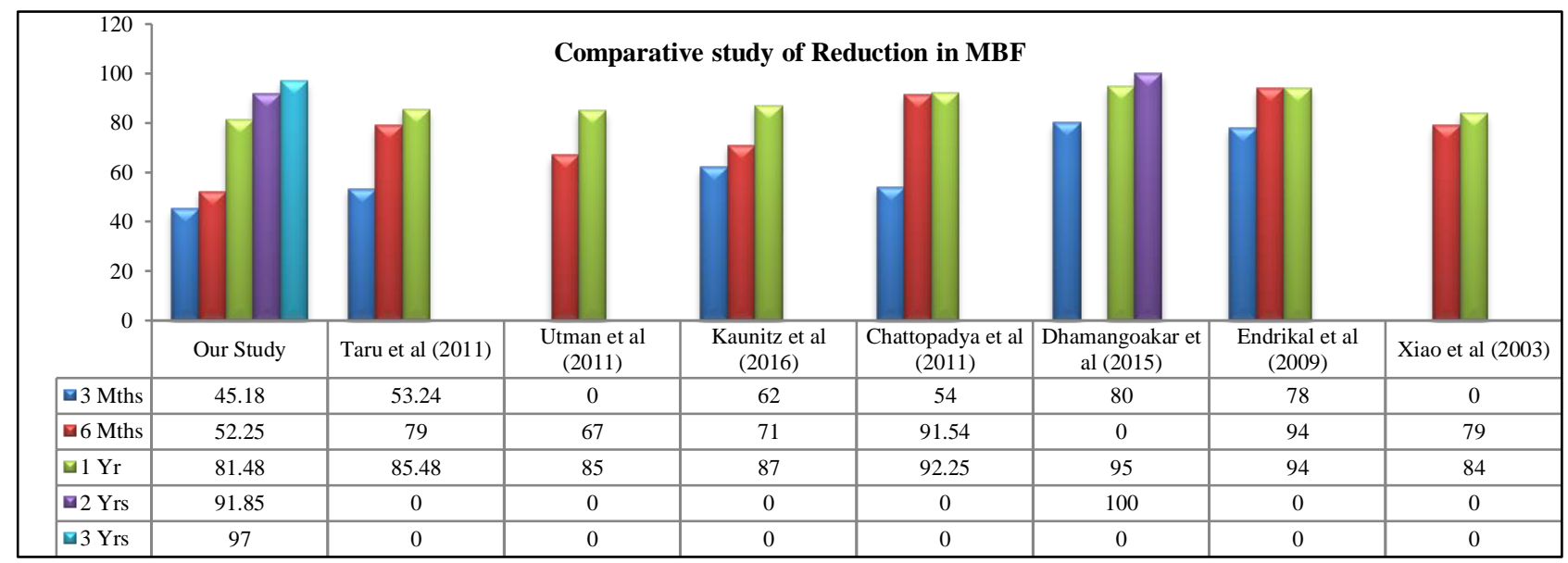

Figure 9: Comparison of reduction in menstrual blood flow (MBF).

Table 2: Comparison of adverse effects.

\begin{tabular}{|c|c|c|c|c|c|c|c|c|c|}
\hline Study ( $\mathrm{n}=$ no. of participants) & 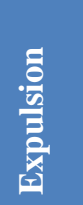 & 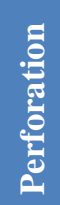 & 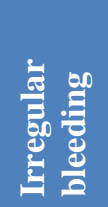 & 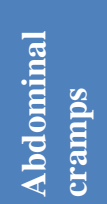 & 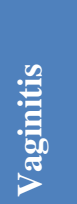 & 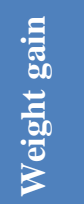 & 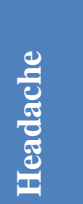 & 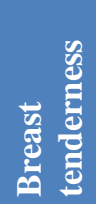 & 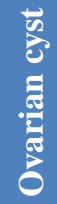 \\
\hline Our study 2020 (n=75) & 4 & 0 & 37.3 & 24 & 5.3 & 2.6 & 9.3 & 3 & 0 \\
\hline Taru et al $2011^{5}(n=70)$ & 4.2 & 0 & 30 & 20 & 6.1 & 3 & 7.69 & 0 & 0 \\
\hline Utman et al $2011(n=60)$ & 10 & 0 & 13 & 0 & 3.33 & 0 & 0 & 0 & 0 \\
\hline Sushil et al $2005^{12}(n=40)$ & 0 & 0 & 22 & 0 & 0 & 5 & 0 & 0 & 0 \\
\hline Kriplani et al $2007^{13}(n=63)$ & 0 & 0 & 71 & 38 & 33.3 & 30.5 & 13.3 & 0 & 0 \\
\hline Kaunitz et al $2010^{7}(\mathrm{n}=82)$ & 5 & 0 & 0 & 0 & 11 & 0 & 10 & 0 & 0 \\
\hline Chattopadyay et $a^{8} 2011(n=42)$ & 2.38 & 0 & 28.5 & 4.76 & 0 & 0 & 0 & 0 & 0 \\
\hline Reid et al $^{14} 2005(n=25)$ & 16 & 0 & 44 & 32 & 0 & 2.6 & 40 & 24 & 24 \\
\hline
\end{tabular}


Table 3: Comparison of continuation rate and satisfaction score in various studies.

\begin{tabular}{|c|c|c|c|c|c|c|c|c|}
\hline & $\begin{array}{l}\text { Our } \\
\text { study }\end{array}$ & $\begin{array}{l}\text { Taru } \\
\text { et }^{5} \mathbf{l}^{5}\end{array}$ & $\begin{array}{l}\text { Utman } \\
\text { et } \mathbf{a l}^{6}\end{array}$ & $\begin{array}{l}\text { Kaunitz } \\
\text { et al }\end{array}$ & 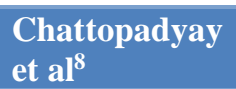 & $\begin{array}{l}\text { Dhamagaonkar } \\
\text { et } \mathbf{a l}^{9}\end{array}$ & $\begin{array}{l}\text { Endrikat } \\
\text { et a } 1^{10}\end{array}$ & $\begin{array}{l}\text { Reid } \\
\text { et } \mathbf{a l}^{14}\end{array}$ \\
\hline Continuation rate & 94.66 & 88.58 & 80 & 96 & 88.1 & 87.14 & 95 & 84 \\
\hline Satisfaction rate & 96.7 & 94.54 & 80 & 85 & 96.3 & 91.42 & 85 & 82 \\
\hline
\end{tabular}

\section{DISCUSSION}

In the present study we found that LNG-IUS was an effective and simple alternative for treatment of menorrhagia. Our findings further proved the efficacy of LNG-IUS in treatment of menorrhagia as in other similar studies. $^{5-11}$ In this study women with AUB, fibroid, adenomyosis, endometriosis, endometrial polyps and previous copper IUCD-induced menorrhagia were included. Figure 9 shows comparison of reduction in menstrual blood flow found in various studies. All groups showed decreased blood loss and eventually improved hemoglobin status and quality of life. In present study dysmenorrhea was relived in the women with adenomyosis and endometriosis.

With LNG-IUS local endometrial concentration of levonorgestrel is high and uniform as compared to blood concentration leading to lesser side-effects. Table 2 presents the comparison of occurrence of various adverse side-effects in our and other studies. . $^{5,12-14}$

Table 3 shows comparison of the continuation rate and satisfaction rate in our and other studies. ${ }^{5-10,14}$ At the end of 3 years $94.66 \%$ of participants continued the use of LNG-IUS with a satisfaction score of $96.7 \%$.

LNG-IUS has significant positive impact on quality of life in form of improved hemoglobin levels within 6 months of use. LNG-IUS is also a very good alternative for women who have HMB and desire contraception as in previous copper IUCD-induced menorrhagia group in our study. ${ }^{15}$ LNG-IUS is useful in treating HMB in obese women. ${ }^{16}$ LNG-IUS is safer option in women with prior surgeries like cesarean and myomectomies. LNG-IUS is beneficial in treatment of diverse causes of HMB like fibroid, adenomyosis, endometriosis, endometrial hyperplasia. ${ }^{17}$

\section{CONCLUSION}

LNG-IUS can be an excellent alternative to medical and surgical treatment modalities for menorrhagia. It drastically reduces the amount of menstrual blood loss within few months of insertion along with improvement in hemoglobin levels. LNG-IUS truly meets the effectiveness and tolerability criteria for being considered as a first choice of treatment option for women with menorrhagia. Side-effects are generally mild and often needs only assurance for continuation of treatment. Due to its reversible and fertility sparing quality it is an emerging option for young women.
LNG-IUS provides a safe, non-surgical, reversible, fertility- sparing, acceptable and cost-effective option in management of menorrhagia.

\section{Future scope}

An unopposed estrogen is an important risk factor for developing atypical hyperplasia and endometrial cancer. ${ }^{18}$ Progesterone counters this effect and local intrauterine progesterone releasing device can be explored as primary therapy for complex atypical hyperplasia and early endometrial cancer. The local atrophic action, reduced mitotic and glandular activity of LNG-IUS can cause regression of histological changes in the endometrium with advantage of preserving uterus in young women who have not completed child-bearing. ${ }^{19,20}$

\section{Funding: No funding sources}

Conflict of interest: None declared

Ethical approval: The study was approved by the Institutional Ethics Committee

\section{REFERENCES}

1. Munro MG, Critchley HO, Broder MS, Fraser IS. FIGO Working Group on Menstrual Disorders. FIGO classification system (PALM-COEIN) for causes of abnormal uterine bleeding in nongravid women of reproductive age. Int J Gynaecol Obstet. 2011;113(1):3-13.

2. Wright RC. Hysterectomy: past, present, and future. Obstet Gynecol. 1969;33(4):560-3.

3. Goñi AZ, Lacruz RL, Paricio JJ, Hernández Rivas FJ. The levonorgestrel intrauterine system as an alternative to hysterectomy for the treatment of idiopathic menorrhagia. Gynecol Endocrinol. 2009;25(9):581-6.

4. Hubacher D, Grimes DA. Noncontraceptive health benefits of intrauterine devices: a systematic review. Obstet Gynecol Surv. 2002;57(2):120-8.

5. Taru G, Nupur G, Sangeeta G, Pushpa B, Jyoti J, Sushma K. (2014) Levonorgestrel intrauterine system (LNG IUS) in menorrahgia: a follow-up study. Open J Obstet Gynecol. 2014;4:190-6.

6. Utman N, Faheem F. Levenorgestrel intra utrine system (LNG IUS) in menorrhagia: a three years followup study. J Postgrad Med Inst. 2011;26(1).

7. Kaunitz AM, Bissonnette F, Monteiro I, Lukkari-Lax E, Muysers C, Jensen JT. Levonorgestrel-releasing intrauterine system or medroxyprogesterone for 
heavy menstrual bleeding: a randomized controlled trial. Obstet Gynecol. 2010;116(3):625-32.

8. Chattopdhyay B, Nigam A, Goswami S, Chakravarty PS. Clinical outcome of levonorgestrel intra-uterine system in idiopathic menorrhagia. Eur Rev Med Pharmacol Sci. 2011;15(7):764-8.

9. Dhamangaonkar PC, Anuradha K, Saxena A. Levonorgestrel intrauterine system (Mirena): an emerging tool for conservative treatment of abnormal uterine bleeding. J Midlife Health. 2015;6:26-30.

10. Endrikat J, Shapiro H, Lukkari-Lax E, Kunz M, Schmidt W, Fortier M. A Canadian, multicentre study comparing the efficacy of a levonorgestrelreleasing intrauterine system to an oral contraceptive in women with idiopathic menorrhagia. J Obstet Gynaecol Can. 2009;31(4):340-347.

11. Xiao B, Wu SC, Chong J, Zeng T, Han LH, Luukkainen $T$. Therapeutic effects of the levonorgestrel-releasing intrauterine system in the treatment of idiopathic menorrhagia. Fertil Steril. 2003;79(4):963-9.

12. Sushil K, Antony ZK, Mohindra V, Kapur A. Therapeutic use of LNG intrauterine system (Mirena) for menorrhagia due to benign lesions-an alternative to hysterectomy. $\mathrm{J}$ Obstet Gynecol India. 2005;55:541-3.

13. Kriplani A, Singh BM, Lal S, Agarwal N. Efficacy, acceptability and side effects of the levonorgestrel intrauterine system for menorrhagia. Int J Gynaecol Obstet. 2007;97(3):190-4.

14. Reid PC, Virtanen-Kari S. Randomized comparative trial of the levonorgestrel intrauterine system and mefenamic acid for the treatment of idiopathic menorrhagia: a multiple analysis using total menstrual fluid loss, menstrual blood loss and pictorial blood loss assessment charts. BJOG. 2005;112(8):1121-5.

15. Tariq N, Ayub R, Jaffery T, Rahim F, Naseem F, Kamal M. Efficacy of levonorgestrel intrauterine system (LNG-IUS) for abnormal uterine bleeding and contraception. J Coll Phys Surg Pak. 2011;21(4):210-3.

16. Vilos GA, Tureanu V, Garcia M, Abu-Rafea B. The levonorgestrel intrauterine system is an effective treatment in women with abnormal uterine bleeding and anticoagulant therapy. J Minim Invas Gynecol. 2009;16(4):480-4.

17. Rodriguez MI, Darney PD. Non-contraceptive applications of the levonorgestrel intrauterine system. Int J Wom Health. 2010;2:63-8.

18. Weiderpass E, Adami HO, Baron JA, Magnusson C, Bergström R, Lindgren A, et al. Risk of endometrial cancer following estrogen replacement with and without progestins. J Nat Cancer Inst. 1999;91(13):1131-7.

19. Orbo A, Vereide A, Arnes M, Pettersen I, Straume B. Levonorgestrel-impregnated intrauterine device as treatment for endometrial hyperplasia: a national multicentre randomised trial. BJOG. 2014;121(4):477-86.

20. Mittermeier T, Farrant C, Wise MR. Levonorgestrelreleasing intrauterine system for endometrial hyperplasia. Cochrane Database Syst Rev. 2020;9:CD012658.

Cite this article as: Bafna BA, Bafna AN.

Levonorgestrel intrauterine system in menorrhagiaan effective and acceptable alternative. Int J Reprod Contracept Obstet Gynecol 2021;10:1665-70. 